\title{
Preparation and Characterization of Microcrystalline Cellulose Produced from Betung Bamboo (Dendrocalamus asper) through Acid Hydrolysis
}

\author{
Rd Roro Altrista Yusrina Kharismi, Sutriyo, Herman Suryadi \\ Faculty of Pharmacy, Universitas INDONESIA.
}

\begin{abstract}
Introduction: Microcrystalline cellulose (MCC) is an excipient used in food, cosmetics and pharmaceutical industries especially in the manufacture of tablet. Dendrocalamus asper (Betung Bamboo) contains high cellulose content at approximately $44.94 \%$ and it has potential as raw material of microcrystalline cellulose. Objective: The purpose of this study was to obtain microcrystalline cellulose powder from betung bamboo and it's physicochemical properties. Methods: The steps to produce microcrystalline cellulose were extraction with n-Hexane: Ethanol (2:1), isolation of alpha cellulose, and acid hydrolysis of alpha cellulose to MCC. The purity of microcrystalline cellulose obtained was identified by infrared spectrophotometry and melting point determination. Other characteristics such as $\mathrm{x}$-ray diffraction, particle size distribution, $\mathrm{pH}$, ash content, moisture content, loss on drying, flow rate, density, scanning electron microscope, and angle of repose were also determined and compared to Avicel PH 101. Results: The Infra-red spectrum obtained were similar to reference Avicel PH 101. The powder was moderately fine, odorless, tasteless and less white compared to reference, particle size distribution $1117.4 \mathrm{~nm}$,
\end{abstract}

$\mathrm{pH} 6.88$, ash contents $\pm 0.0584 \%$, moisture content $36 \%$, loss on drying $4.59 \%$. Density, flow rate and angle of repose fulfilled the requirements based on the literature. Conclusion: There is a similarity characteristic of MCC obtained and reference. So, there is a possibility for its use as excipient in the future by doing the application studies in food and pharmacy.

Key words: Acid hydrolysis, Bamboo betung, Cellulose, Characterization, Microcrystalline cellulose.

\section{Correspondence}

Herman Suryadi, Laboratory of Microbiology and Biotechnology, Faculty of Pharmacy, Universitas Indonesia, Depok 16424, INDONESIA.

Phone: +62-21-7270031

Email: hermans001@yahoo.com

DOI: 10.5530/jyp.2018.2s.15

\section{INTRODUCTION}

Microcrystalline cellulose is an important additional excipients in pharmaceuticals, cosmetics, food and other industries. Microcrystalline cellulose can be used as an additive in food and cosmetics and also used as tablets excipient. ${ }^{1,2}$ Microcrystalline cellulose, as a filler, will produce tablets with high hardness, slight friability, rapid disintegration time, and high percentage of drug release. Moreover, microcrystalline cellulose commonly used for the manufacture of direct compression tablets. ${ }^{3}$ The popularity of direct compression as a process of manufacturing tablets is increasing because it has many advantages such as: providing a uniform particle size, does not require the granulation process, producing more stable tablet, and profitable in economical point of view. Besides that, microcrystalline cellulose can reduce sedimentation in suspension and dry syrup. ${ }^{4,5}$ In Indonesia, 100 billion tons of cellulose production are needed per year. ${ }^{3}$ In addition, this country depends on exports to fulfill of microcrystalline celulose, which may impact on drug prices in the market. This condition is very unfortunate because there are a lot of prospective cellulose source from local raw materials in Indonesia.

In general, wood and cotton powder is a common source for the production of microcrystalline cellulose. The cellulose content of cotton is $95-99 \%$, that of wood is $40-50 \%$, and that of bark is $20-30 \%{ }^{6,7}$ The use of wood is considered less effective because it could reduce the availability of wood and lead to massive deforestation, cause ecological imbalances. Therefore, it is necessary to find the source of alternative non-wood source in the manufacture of microcrystalline cellulose, one of which is bamboo.

In Indonesia, bamboo has been used for very long time. ${ }^{8}$ One type of bamboo that is widely spread in Indonesia is bamboo betung. Chemical content of bamboo is cellulose $42.4 \%-53.6 \%$, holocellulose $50-70 \%$ and lignin $19.8 \%$ - 26.6\%. ${ }^{9}$ Chemical content of bamboo betung holocellulose $73,63 \%$, a-cellulose $44,94 \%$, lignin $27,37 \%$, ash $4,63 \%$, silica $3,51 \% .{ }^{10}$

Microcrystalline cellulose is manufactured by controlled hydrolysis with dilute mineral acid solutions of $\alpha$-cellulose which can be obtained from various sources, such as plants or microorganisms fermentation. ${ }^{11}$ Cellulose can be made into microcrystalline cellulose. The aims and objectives of this study were to obtain microcrystalline celullose from betung bamboo to find its identity and characteristics as an excipient compared to the commercial standard one, Avicel PH 101.

\section{MATERIAL AND METHODS}

\section{Equipment}

Bulk-tapped densitometer, desiccator, Differential Scanning Calorimetry Perkin Elmer, Flowmeter, Hot plate, filter paper, krusibel, oven, sieving, pH meter, Particle Size Analyzer, FT-IR spectrophotometer Hitachi 270-50, furnaces, analytical balance (Acculab), XRD D8 Advanc A25 Bruker, SeM JEOL JSM-6510 series, waterbath, pipette volume and other glass tools commonly used in the Laboratory. 


\section{MATERIAL}

\section{Raw material}

Raw materials used in this research wasbetung bamboo powder obtained from Badan Penelitian Tanaman Rempah dan Obat (BALITRO). The powder was sifted back to its homogenous condition.

\section{Chemical material}

The chemicals used are sodium hydroxide (BRATACO), Hydrochloric Acid (BRATACO), sodium hypochlorite (BRATACO), Nitric Acid (BRATACO), Sodium nitrite (Asian Chemical), Sodium sulphites (Asian Chemical), Ethanol 96\% (BRATACO), n - hexane (BRATACO), KBr powder, iodinized zinc chloride solution, aquadestilata (BRATACO) and avicel PH 101 as standard.

\section{Extraction}

To find the best extraction method, three type of extraction methods were done using: (1) Decoction Extraction, (2) Maseration with Ethanol, and (3) Maseration with Ethanol: n-heksan (2: 1)..$^{12,13}$

\section{Isolation of a-cellulose}

For every $\pm 50 \mathrm{~g}$ of extracted bamboo powder, $3.5 \%$ nitric acid (containing $6.7 \mathrm{mg}$ sodium nitrite) of $670 \mathrm{~mL}$ was added to the Erlenmeyer flask. The mixture then immersed in a water bath for $2 \mathrm{~h}$ at $90^{\circ} \mathrm{C}$. The insoluble part was separated by filtration and the residual obtained was washed with distilled water. The residue was immersed into $500 \mathrm{ml}$ of a mixed solution containing sodium hydroxide and sodium sulfite each $2 \% \mathrm{w} / \mathrm{v}$ at $50^{\circ} \mathrm{C}$ for $1 \mathrm{~h}$. Repeat the filtering and washing processes as described before to obtain residue. The residue was bleached by mixing it into the mixture of $400 \mathrm{~mL}$ of water and $3.5 \% \mathrm{w} / \mathrm{v}$ sodium hypochlorite (water and $3.5 \%$ sodium hypochlorite solution ratio is $1: 1$ ), then the mixture was heated until boiling for $10 \mathrm{~min}$ followed by filtration and washing. The residue obtained from the filtration was heated at $80^{\circ} \mathrm{C}$ into $400 \mathrm{~mL}$ of sodium hydroxide $17.5 \mathrm{w} / \mathrm{v}$ for $30 \mathrm{~min}$. Then the solution was filtered and washed. The extraction process was then continued by bleaching process. Perform filtering and washing until the residue is clean. Subsequently, the residue was dried at $60^{\circ} \mathrm{C}$ and an alpha-cellulose is obtained. Weigh alpha cellulose and calculate the yield. ${ }^{13}$

\section{Acid hydrolysis}

A total of $50 \mathrm{~g}$ of alpha-cellulose was hydrolyzed with $2.5 \mathrm{~N}$ hydrochloric acid $(1,2 \mathrm{~L})$. The solution was simmered for $15 \mathrm{~min}$ in a glass beaker. The hot mixture is poured into cold water while strongly stirred by spatula and then stored overnight. The obtained microcrystalline cellulose was washed with distilled water until neutral and filtered, then driedwith oven at a temperature of $57-60^{\circ} \mathrm{C}$ for $60 \mathrm{~min}$ and then homogenized. The microcrystalline cellulose obtained is stored at room temperature in the desiccator. ${ }^{13,14}$

\section{Identification and Characterization of the microcrystalline cellulose}

\section{a. Organoleptic}

The MCC obtained was placed on a white base, and then the shape or appearance, color, taste, smell were observed. ${ }^{15}$

\section{b. Infrared Spectrum Observation}

The standard andMCC obtained was weighed about $1 \mathrm{mg}$ and mixed homogenously with $99 \mathrm{mg} \mathrm{KBr}$ and then compressed into thin disc that are ready to measure IR spectrum of bamboo powder is compared with IR Avicel PH 101 spectrum using FT-IR spectrophotometer Hitachi $270-50 .{ }^{16}$

\section{c. XRD analysis}

About $2 \mathrm{~g}$ of the pounded MCC obtained was placed and measured using XRD Bruker D8 Advance Eco Diffractometer. It was operated in reflection mode $(40 \mathrm{kV}, 35 \mathrm{~mA})$ and used $\mathrm{Cu}-\mathrm{Ka}$ radiation lamp $\left(\left(\mathrm{l}_{1}=1.54060 \AA\right.\right.$ and $\left.l_{2}=1.54439 \AA\right)$. The result of diffraction pattern was compared with the Powder Diffraction File database to find out the crystal size in the sample. The test was repeated using Avicel PH 101 as standard.

\section{d. Scanning Electron Microscope (SEM)}

The MCC obtained was prepared in the form of dried powder and sprinkled as thinly as possible on the Carbon Tabs. Then, the sample was coated with the Quorum Q150R ES Sputter Coater tool. Coating was carried out using gold material with $20 \mathrm{~mA}$ current sputter and sputter time $60 \mathrm{sec}$. The coated sample was then mounted in the stage for analysis. Picture was taken with SEM (JEOL JSM-6510 series). The detector used was secondary electron with a working distance of $9.0 \mathrm{~mm}$ and an EHT of $16 \mathrm{kV}$. The test was repeated using Avicel PH 101 as a standard.

\section{e. Analysis of particle size}

Particle size of MCC obtained is compared to particle size of Avicel PH 101 using Malvern Zetasizer ZS200. Preparation of the powder was performed by dispersing the crystal powder in an appropriate medium which can disperse sample powders and in this study, distilled water was used.

\section{f. Starch Test}

A total of $\pm 10 \mathrm{mg}$ powder was added $90 \mathrm{ml}$ of aquadest and heated for $15 \mathrm{~min}$. Then it was filtered while still hot. Let it cool and then added by $0.1 \mathrm{~mL}$ iodine filtrate. Both the standard and MCC obtained powder were tested If the filtrate was turned out into blue color indicated that the result was negative. ${ }^{15}$

\section{g. Acidity}

Two $g$ of both the standard and MCC obtained powder is added in $100 \mathrm{~mL}$ of distilled water, shake for $5 \mathrm{~min}$ and measured $\mathrm{pH}$ with $\mathrm{pH}$ meter. ${ }^{17}$

\section{h. Water content}

Water content was measured using Moisture Content tool with temperature setting at $105^{\circ} \mathrm{C}$. The requirement of both the standard and MCC obtained powder water content is not more than $5.0 \%{ }^{17}$

Water content $=100 \%-\mathrm{x}$

Description: $\mathrm{x}$ is the number read on the tool

\section{i. Ash content}

Two - three g of samples (W) are weighed in the cup, then the cup containing the sample is ignited until gray ash is obtained or until the weight is constant. The ignition was carried out at $600^{\circ} \mathrm{C}$ for $6 \mathrm{~h}$. The requirement of both the standard and MCC obtained powder ash content is not more than $0.1 \%{ }^{17}$

$$
\text { Ash content }=\frac{\mathrm{wi}-\mathrm{wo}}{\mathrm{w}} \times 100 \%
$$

Information:

$\mathrm{W}=$ sample weight $(\mathrm{g})$

Wo $=$ constant empty crass weight $(\mathrm{g})$

$\mathrm{Wi}=$ constant weight crucial with ash $(\mathrm{g})$

\section{j. Particle Density Test}

Weighed both the standard and MCC obtained powderas much as $\pm 15 \mathrm{~g}$, put into a measuring cup then recorded volume (bulk volume / Vb). Polygonal grounded glasses were placed on the bulk-tapped density tool, the tool was turned on and set to 300 beats / min, then recorded the tapped volume (Sulaiman, 2007). Calculated Bulk Density (DB) and Tapped Density (DT) with the formula: 


$$
\mathrm{Db}=\frac{\text { Powder weight }(\mathrm{g})}{\mathrm{Vb}(\mathrm{mL})} \quad \mathrm{Dt}=\frac{\text { Powder weight }(\mathrm{g})}{\mathrm{Vt}(\mathrm{mL})}
$$

\section{k. Flow rate}

Both the standard and MCC obtained powder, weighed around $\pm 25 \mathrm{~g}$, is fully inserted into the flowmeter. The flowmeter is switched on, then the time it takes until all of the powders flow down is recorded. ${ }^{18}$

\section{Angle of repose}

Both the standard and MCC obtained powder, weighed around \pm 15 , is carefully poured into the flowmeter funnel. The end cover of the funnel is opened slowly so that the powder flows down slowly. The height and diameter formed are measured. ${ }^{18}$

\section{m. Loss on drying}

A total of $1 \mathrm{~g}$ of sample (standard and MCC obtained) is inserted in porcelain crucible, then dried in oven atemperature $100-105^{\circ} \mathrm{C}$ until obtained constant weight. ${ }^{15}$ Percentage of drying can be calculated by the formula:

$$
\mathrm{X}=\frac{(\mathrm{B}-\mathrm{A})-(\mathrm{C}-\mathrm{A})}{(\mathrm{B}-\mathrm{A})} \times 100 \%
$$

$\mathrm{A}=$ Weight empty crucible $(\mathrm{g})$

$\mathrm{B}=$ Crucible weight + sample before dried $(\mathrm{g})$

$\mathrm{C}=$ Crucible weight + sample after dried $(\mathrm{g})$

\section{RESULT}

\section{Extraction, Isolation of a-cellulose and Acid Hydrolysis}

Based on the yield obtained from the extraction method, it showed that the extraction method could affect the yield of microcrystalline cellulose obtained. The yield of $\alpha$-cellulose obtained from the three kinds of preparation methods with each $\pm 50 \mathrm{~g}$ sample are shown in Table 1 .

The best yield of MCC was obtained from the maceration method with n-hexane: ethanol (2: 1), with $\alpha$-cellulose and microcrystalline cellulose yields were $28.6 \%$ and $53.6 \%$, respectively. Therefore, this method of extraction was used for further process.

\section{Identification and Characterization}

Based on identification and characterization result, it showed that the characteristic of standard powder was relatively similar with the MCC obtained. The standard powder was fine, quite white, odorless and tasteless, but the MCC obtained was not as white as standard reference Avicel PH101 (Figure 1).

The comparison between the infrared spectra of standard reference and MCC obtained was shown in Figure 2. It showed that the infrared spectra of MCC obtained was similar to the infrared spectra of standard. The structures of the fingerprint region between $899-670 \mathrm{~cm}^{-1}$ show the C-O$\mathrm{C}$ ring of the pyranose ring, and the peak of $800-900 \mathrm{~cm}^{-1}$ for $\beta$-glycoside bonds was also observed which was particularly characteristic for microcrystalline cellulose compounds.

The standard XRD graph based on Figure 3, exhibited a sharp peak showing the crystalline property of standard (value of $2 \Theta$ of 22.53) and a broad peak showing the amorphous property of standard (value of $2 \Theta$ of 15.64). While in the MCC obtained XRD graph illustrated in Figure 3 demonstrated a sharp peak showing crystal $(2 \Theta$ value were 20,140 and 22,31 ) and amorphous (value of $2 \Theta$ about 16,28) forms. The shape of the graph curves at the peak of the hydrolysis sample with standard had shown similarities in its amorphous and crystalline form as illustrated in Figure 3.
Table 1: The result of a-cellulose rendementof the three preparation methods.

\begin{tabular}{ccc}
\hline No & Methods & Rendement a-selulosa(\%) \\
\hline 1 & decoction & $7.26 \% ;$ \\
& & $9.61 \%$ \\
2 & Maseration with Ethanol & $11.95 \%$ \\
& & $14.32 \%$ \\
3 & Maseration with n-Hexane : & $25.54 \%$ \\
& Ethanol ( $2: 1)$ & $28.59 \%$
\end{tabular}

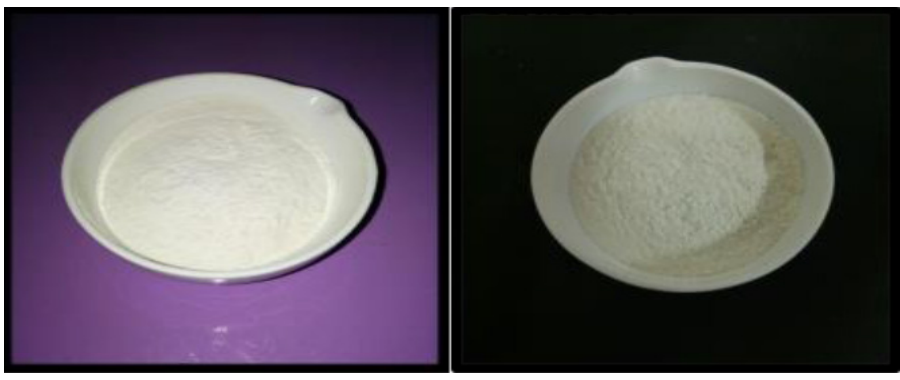

Figure 1: Organoleptic of standar (A) and MCC obtained (B).

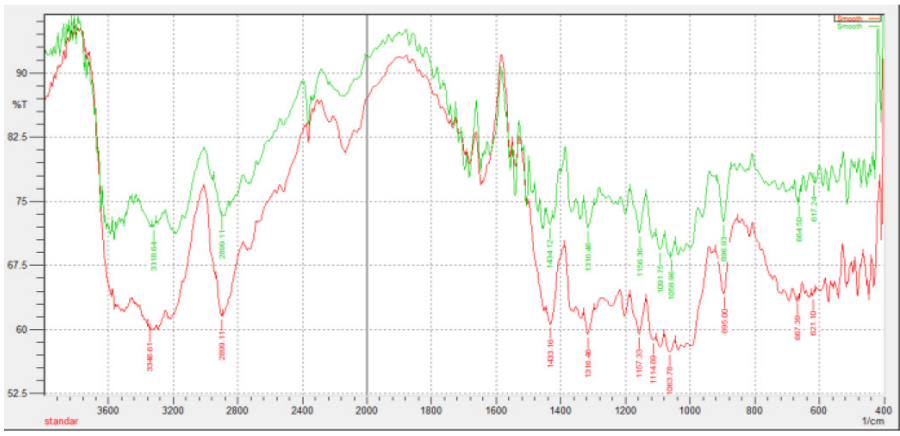

Figure 2: The infrared spectra of the MCC obtained (green spectrum)results were compared with the standard(red spectrum).

The result of SEM analysis showed that microcrystals had been formed in MCC obtained. Based on SEM analysis results in Figure 4, the hydrolysis MCC particles were rods with cylindrical shapes with rough surfaces. Standard was found to exhibit uniform and more spheric particle size than the hydrolyzed sample. Differences in MCC obtained and standard morphology may due to difference in raw material source and difference in MCC preparation methods

The results of particle size distribution, both standard and MCC obtained results had smaller particle size than the specified requirements. It was also showed that the sample had smaller particle size than the standard. The starch test results showed that both of the standard and the MCC obtained were not forming blue-violet color.

Based on $\mathrm{pH}$ test result, standard solution $\mathrm{pH}$ was 6.99 and 6,96 , while $\mathrm{pH}$ of MCC obtained was 6,88 and 6,87. This meant that the result of the hydrolysis sample met the specified $\mathrm{pH}$ requirements of $\geq 5,0$ and $\leq 7.5$.

The average moisture content obtained by standard was $4.12 \%$ while the MCC obtained water content was $4.36 \%$. This showed that the water content of the hydrolysis sample results met the existing requirement of $\leq 5 \%$.

The ash content obtained for the standard was $0.0421 \%$ and $0.0584 \%$ for the MCC obtained. Ash requirement that must be fulfilled was $\leq 0,1 \%$. 


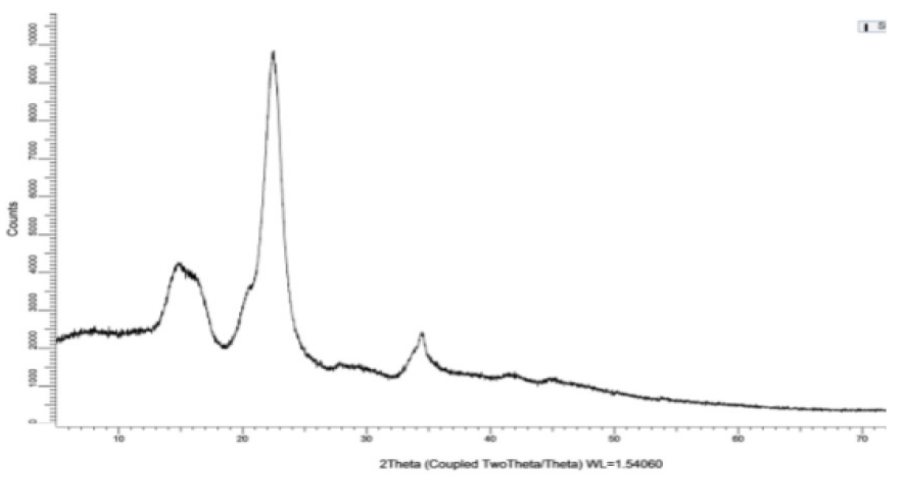

(A)

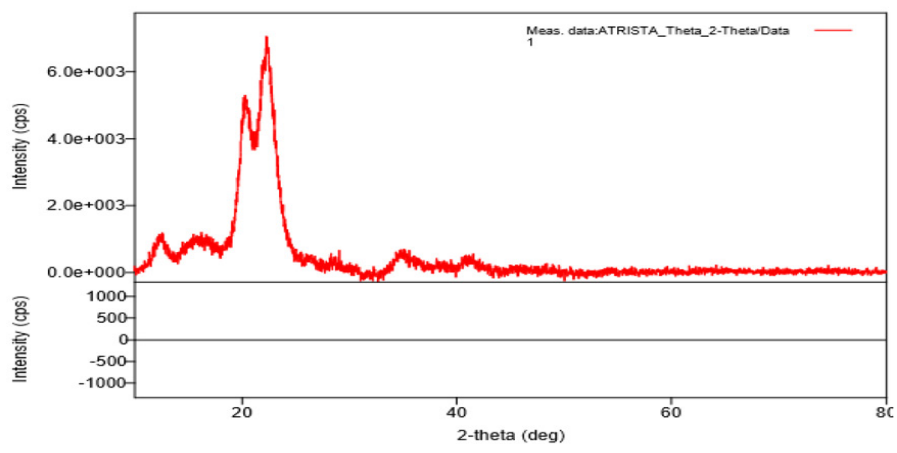

(B)

Figure 3: Diffractogram of standard (A) and MCC obtained(B),

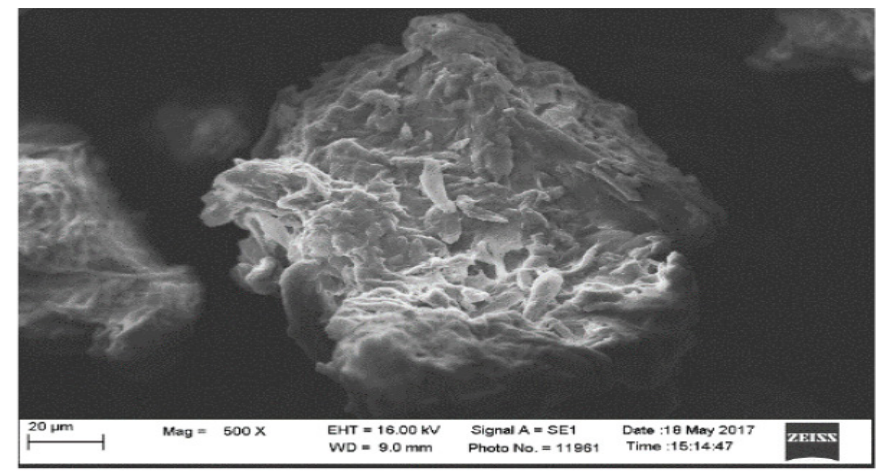

(A)

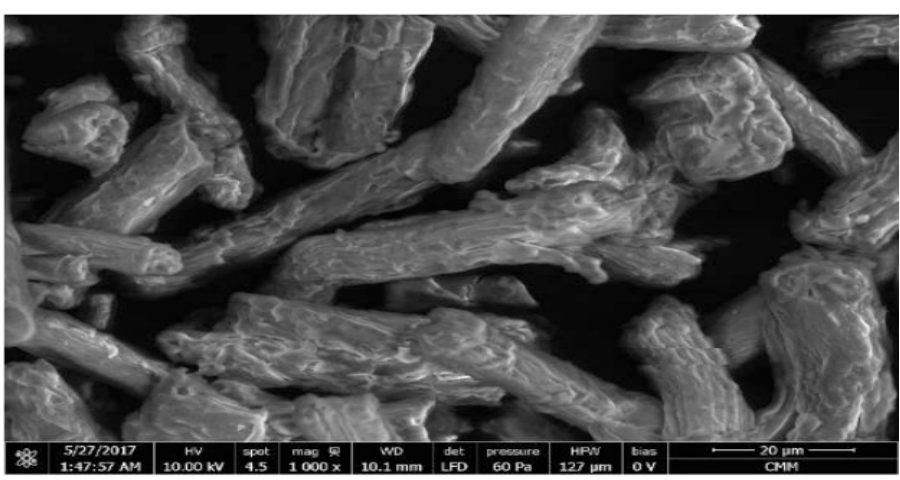

(B)

Figure 4: Result of SEM analysis of standar (A) and MCC obtained (B).
Table 2: The results of size and particle size distribution of standard and MCC obtained.

\begin{tabular}{ccccc}
\hline & $\operatorname{dv10}(\mathrm{nm})$ & $\mathrm{dv50}(\mathrm{nm})$ & $\mathrm{dv90}(\mathrm{nm})$ & $\mathrm{dv100}(\mathrm{nm})$ \\
\hline Avicel PH 101 & 33.6 & 43,3 & 1380 & 720 \\
MCC obtained & 154.7 & 187.1 & 247.7 & - \\
\hline
\end{tabular}

Table 3: Result of particle density test of standard and MCC obtained.

\begin{tabular}{cccccc}
\hline & $\begin{array}{c}\text { Bulk } \\
\text { Density } \\
\left(\mathbf{g} / \mathbf{c m}^{3}\right)\end{array}$ & $\begin{array}{c}\text { Tapped } \\
\text { Density } \\
\left(\mathbf{g} / \mathbf{c m}^{3}\right)\end{array}$ & $\begin{array}{c}\text { Carr's } \\
\text { Index }\end{array}$ & $\begin{array}{c}\text { Hausner } \\
\text { ratio }\end{array}$ & $\begin{array}{c}\text { (USP 29-NF } \\
\mathbf{2 4}, \mathbf{2 0 0 5 )}\end{array}$ \\
\hline Standard 1 & 0.336 & 0.433 & $22 \%$ & 1.29 & Passable \\
Standard 2 & 0.336 & 0.437 & $23 \%$ & 1.30 & Passable \\
$\begin{array}{c}\text { MCC } \\
\text { obtained 1 } \\
\text { MCC } \\
\text { obtained 2 }\end{array}$ & 0.320 & 0.465 & $31 \%$ & 1.45 & Poor \\
\hline
\end{tabular}

The standard and MCC obtained met the requirements. This indicated that the sample was sufficiently pure.

The bulk and tapped density results of both the standard and the MCC obtained were in accordance with the requirements in the literature with bulk density ranges of $0.25-0.50 \mathrm{~g} / \mathrm{cm}^{3}$ and the range of tapped density values was $0.33-0,70 \mathrm{~g} / \mathrm{cm} 3$. The particle density test showed Carr's index value and hausner ratio was not satisfactory. The standard belong to the fairly good category of flow properties, while MCC obtained belongs into the category of poor flow properties. This may be due to the particle size factor of MCC obtained greater than the standard which influences the sample particle density so that it became uncertain (Table 2 and Table 3).

The test results of both standard and MCC obtained results were different from the literature. The average standard has flow rate of $1.59 \mathrm{~g} / \mathrm{s}$, whereas MCC obtained had flow rate of $1.38 \mathrm{~g} / \mathrm{s}$. The results showed that the standard had a better flow rate velocity than MCC obtained. It can be concluded that the standard characteristic of standard had better flow rate characteristic than MCC obtained.

The results of angle of repose of both standard and MCC obtained were different from the literature, but both were better and were included in the excellent and good classification. The average standard result angle of repose was $30,74^{\circ}$ and for sample of hydrolysis result was $31,39^{\circ}$. The results show that the standard has better angle of repose than MCC obtained.

The loss on drying test for standard is 6,01\% and for MCC obtained is equal to $4,59 \%$ This shows that both standard and MCC obtained fulfill requirement for loss on drying of $\leq 7.0 \%$.

\section{DISCUSSION}

The bamboo powder was washed and dried so that the sample used was clean and did not mix with impurities. Afterwards, $\pm 50 \mathrm{~g}$ of bamboo powder was prepared by three different extraction methods namely: decoction, maceration with ethanol solvent, and maceration with the mixture of n-hexane: ethanol (2: 1). Extraction was done to remove extractives substances contained in bamboo powder such as phenolics, fats, proteins, terpenes, and waxes. Removing extractive substances can reduce the bond strength between the fibers and increase the alkali consumption. ${ }^{19}$ 
The process was continued by delignification to a final $\alpha$-cellulose isolation. The extracted bamboo powder was added with $670 \mathrm{~mL}$ of $3.5 \%$ nitric acid in a glass beaker, heated in waterbath at $90^{\circ} \mathrm{C}$. Nitric acid was an excellent agent for the delignification process because it is able to remove lignin in the form of nitro lignin. However, nitric acid reacts very quickly with cellulose. Therefore, it is necessary to add its salt sodium nitrite to prevent the reaction with cellulose and the lignin degradation process can be accelerated. ${ }^{19}$ Unfortunately this process could not eliminate lignin completely.

Therefore, the delignification proccess is continued by addition of $250 \mathrm{~mL}$ $2 \%$ sodium sulfite, and maintained the $\mathrm{pH}$ at about $7-10$ by adding sodium hydroxide. This process can selectively eliminate lignin up to $50 \%$. The bleaching process was then performed with $400 \mathrm{~mL}$ mixture of $3.5 \%$ sodium hypochlorite and water (1: 1$)$. The process can remove the residue of lignin in the pulp to obtain holocellulose. ${ }^{19}$

The next proccess was carried out to separate $\alpha$-cellulose, $\beta$-cellulose and $\gamma$-cellulose, by using $400 \mathrm{~mL} 17.5 \%$ sodium hydroxide. $\alpha$-cellulose is insoluble while $\beta$-cellulose and $\gamma$-cellulose are soluble. ${ }^{19}$ The $\alpha$-cellulose was obtained by filtration. The last step of $\alpha$-cellulose isolation was re-bleaching with a $400 \mathrm{~mL}$ mixture of $3.5 \%$ of the sodium hypochlorite and water (1: 1) to fine-tune the yield of $\alpha$-cellulose obtained and bleach the $\alpha$-cellulose product.

The $\alpha$-cellulose obtained was then conversed to MCC by hydrolysis with $2.5 \mathrm{~N} \mathrm{HCl}$ for $10 \mathrm{~min}$. Hydrolysis make the a-cellulose does not turned into simple sugars glucose but into microcrystalline cellulose, and make the absence of blue-purple color in the starch test due to the breaking of carbohydrate chains into shorter chains. $\mathrm{HCl}$ was used because it has suitable reactivity in the hydrolysis process compared to nitric acid and sulfuric acid. In addition, it was quite cheap and easy to obtain. After finishing hydrolysis, the hot mixture was poured into cold water while stirring strongly by spatula and then stored overnight. Then the suspension was filtered and washed many times until the solution became neutral $(5,0 \leq \mathrm{pH} \leq 7.5)$, and continued by drying at $60^{\circ} \mathrm{C}$ for $24 \mathrm{~h}$. Drying process was very important to perform because if the water content was too high it might facilitate bacteria, mold and yeast to reproduce and might affect the stability of substance. In addition, it may disrupt with the nature of hydrophobicity and tablets disintegration time later. The higher the moisture content, the higher the hydrophobicity, so the tablets were difficult to be disintegrated during dissolution and distributed in the body.

\section{CONCLUSION}

Based on the results obtained from this study, it can be concluded that the extraction method affects the yield of $\alpha$-cellulose. And the most optimum method of extraction is maceration with a mixture of $n$-hexane solvent: ethanol (2: 1). The yield of microcrystalline obtained is $15.05 \%$ of 301.42 g. Compared to the standard reference Avicel PH101 there were a slightly differences in characteristic of MCC obtained which could be attributed by the differences in the source of material and method of preparation.

\section{ACKNOWLEDGEMENT}

The authors thank to Publikasi Internasional Terindeks Untuk Tugas Akhir Mahasiswa (PITTA) 2017 provided by the Directorate of Research and Community Engagement, Universitas Indonesia for the financial support to this study.

\section{CONFLICT OF INTEREST}

The authors declare no conflict of interest.

\section{ABBREVIATIONS}

MCC: Microcrystalline cellulose; IR: Infra-Red; KBr: Potassium bromide.

\section{SUMMARY}

- The extraction method affects the yield of $\alpha$-cellulose, and the most optimum method of extraction is maceration with a mixture of $\mathrm{n}$ hexane solvent: ethanol (2: 1).

- The powder was moderately fine, odorless, tasteless and less white compared to reference, and the Infra-red spectrum obtained were similar to reference Avicel PH 101. There is a similarity characteristic of MCC obtained and reference.

- Dendrocalamus asper has potential as raw material of microcrystalline cellulose.

\section{REFERENCES}

1. Kian LK, Jawaid M, Ariffin $\mathrm{H}$, Alothman OY. Isolation and characterization of microcrystalline cellulose from roselle fibers. Int J Biol Macromol. 2017;103:931-40.

2. Nsor-Atindana J, Chen M, Goff HD, Zhong F, Sharif HR, Li Y. Functionality and nutritional aspects of microcrystalline cellulose in food. Carbohyd Polym. 2017:172:159-74.

3. Boluk Y. Nanocellulose an Investigative Summary. Impact of Nanotechnology in Alberta. Thecis Nanotechnology and Bio-Industries. Workshop. 2010.

4. Ohwoavworhua FO, Adelakun TA, Okhamafe AO. Processing pharmaceutical grade microcrystalline cellulose from groundnut husk: Extraction methods and characterization. Int J Green Pharm. 2009;3(2):97-104.

5. Voigt R. Buku Pelajaran Teknologi Farmasi. $5^{\text {th }}$ ed. Yogyakarta: Gadjah Mada Press. 1994

6. Avérous L, Le Digabel F. Properties of bio composites based on lignocellulosic fillers. Carbohyd Polym. 2006;66(4):480-93.

7. Khalil HA, Bhat AH, Yusra Al. Green composites from sustainable cellulose nanofibrils: A review. Carbohyd Polym. 2012;87(2):963-79.

8. Swara P. Pengawetan Kayu dan Bambu. KDT Jakarta. 1997.

9. Liese W. The Structure of bamboo in relation to its properties and utilization: Bamboo and its use. International Symposium on Industrial Use of Bamboo. Beijing. 1992:7-11.

10. Manuhuwa E, Loiwatu M. Komponen kimia dan anatomi tiga jenis bambu Universitas Pattimura. Maluku. 2007:(11).

11. Rowe, RC, Sheskey PJ, Quinn ME. Handbook of Pharmaceutical Excipients. $6^{\text {th }}$ ed. Washington DC and London: American Pharmacist Association and Pharmaceutical Press. 2009.

12. Gupte NJ, Baichwal MR. Cellulose processing and application. India J Pharm. $1975 ; 37(4): 81-4$

13. Ohwoavworhua FO, Adelakun TA. Non-wood fibre production of microcrystalline cellulose from Sorghum caudatum: Characterisation and tableting properties. Indian J Pharm Sci. 2010;72(3):295-301.

14. Taherzadeh MJ, Karimi K. Acid Based Hydrolysis Processes for Ethanol from Lignocellulosic Materials: A Review. Bioresour. 2007;2(3):476-99.

15. Stationery Office (Great Britain). British pharmacopoeia 2002. London: Stationery Office. 2002.

16. Dirjen PO. Departemen Kesehatan Republik Indonesia. Farmakope Indonesia. $3^{\text {rd }}$ ed. Jakarta: Departemen Kesehatan Republik Indonesia. 1979.

17. Harmita. Analisis Kuantitatif Bahan Baku dan Sediaan Farmasi. Jakarta: Departemen Farmasi FMIPA Universitas Indonesia. 2006.

18. Lachman L, Herbert AL, Joseph LK. Teori dan praktek farmasi industri. Jakarta: Universitas Indonesis Press. 1994;150(161):658.

19. Sun $Y$, Cheng J. Hydrolysis of lignocellulosic materials for ethanol production: a review. Bioresour Technol. 2002;83(1):1-11. 